\title{
EFFECT OF STRUCTURE AND PROPERTIES OF ALUMINIUM-LITHIUM ALLOY WELDED JOINTS PRODUCED BY ARGON-ARC AND FRICTION STIR WELDING METHODS
}

\author{
L.I. MARKASHOVA, A.G. POKLYATSKY and O.S. KUSHNARYOVA \\ E.O. Paton Electric Welding Institute, NASU \\ 11 Kazimir Malevich Str., 03680, Kiev, Ukraine. E-mail: office@paton.kiev.ua
}

\begin{abstract}
An essential difference in formation of structural-phase state at application of different welding conditions - friction stir welding compared to argon-arc welding - is considered in the case of welded joints of complex aluminium-lithium alloys. The urgency of comprehensive experimental-analytical assessment of interrelation of welded joint structure and properties is also shown. Assessments of specific contribution of structural-phase state (chemical composition, phase dimensions, grain, subgrain and dislocation structure) into the change of the main service properties of welded joints made by argon-arc welding and friction stir welding are considered, as well as the influence of welded joint structural state on the nature of distribution, level of growing internal stresses and their relaxation mechanisms under specific welding conditions. 10 Ref., 5 Figures.
\end{abstract}

Keywords : aluminium alloy, FSW, TIG welding, weld metal, phase precipitates, structure, dislocations, strengthening, strength characteristics, crack resistance

Welded joints of complex aluminium alloys, extensively applied in aircraft and aerospace engineering and operating, as a rule, under complex operation conditions, should provide reliable mechanical properties of welded structures, that is mainly determined by structural-phase state of welding zone, formed during the applied technological operations, namely alloying, welding conditions, etc. [1]. In this respect, the issue of structure influence on properties is extremely urgent, particularly for welded joints of complex aluminium alloys. These alloys are characterized by an abrupt change not only of structures, but also of phase precipitates (PP) during various technological operations, including the influence of welding processes.

To assess the role of technological modes used in friction stir welding (FSW), in the change of welded material properties, namely strength, ductility and crack resistance characteristics [2-6], it appears appropriate to compare the dependencies of welding modes $\leftrightarrow$ joint properties with similar interconnections studied (and in sufficient detail) for the regularly used processes of aluminium alloy welding, to which TIG welding belongs.

Material and procedures. To compare the influence of different welding modes on welded joint properties, investigations were performed on welded joints of complex Al-Li alloys $1460(\%$ : Al-3Cu$2 \mathrm{Li}-0.08 \mathrm{Sc}$ ) produced by TIG welding in MW-450 unit (Fronius, Austria) under the following condi- tions: $20 \mathrm{~m} / \mathrm{h}$ speed and 140 A current at application of Sv1201 and Sv1201 + $0.5 \%$ Sc fillers. Structure-phase state of welded joints made by FSW without the filler in laboratory unit designed at PWI was studied in parallels. In the latter case a special tool with a conical tip and $12 \mathrm{~mm}$ diameter shoulder was used to produce butt joints, tool rotation speed here being equal to $1420 \mathrm{rpm}$, and linear speed of its movement along the butt being $14 \mathrm{~m} / \mathrm{h}$.

Complete experimental data on structural-phase state of welded joint metal was derived with application of the methods of light, analytical scanning (SEM-515, Philips, The Netherlands), as well as microdiffraction transmission electron microscopy (JEM-200CX, JEOL, Japan) with accelerating voltage of $200 \mathrm{kV}$.

Proceeding from the complex of investigations, analytical assessments of specific (differentiated) contribution of different structural factors and their parameters (chemical composition, volume fraction and phase precipitate dimensions, grain, subgrain and dislocation structure) into the change of service characteristics of welded joints were performed on all structural levels.

Analytical assessment of the total (integral) value of yield point $\Sigma \sigma_{\mathrm{y}}$ was performed using the known dependence $[7-10]$ :

$$
\Sigma \sigma_{\mathrm{y}}=\Delta \sigma_{0}+\Delta \sigma_{\mathrm{s} . \mathrm{S}}+\Delta \sigma_{\mathrm{gr}}+\Delta \sigma_{\mathrm{s}}+\Delta \sigma_{\mathrm{d}}+\Delta \sigma_{\mathrm{d} . \mathrm{h}},
$$




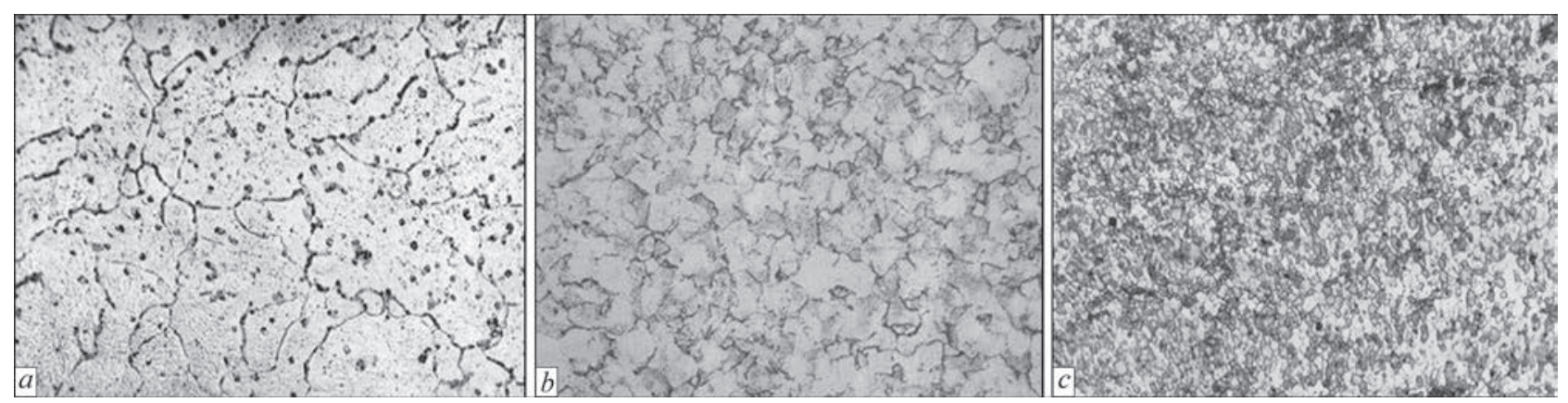

Figure 1. Microstructure $(\times 500)$ of metal of Al-Li alloy 1460 welds produced by TIG welding with application of Sv1201 (a) and Sv1201 + 0.5Sc $(b)$ filler wire and by FSW $(c)$

including $\Delta \sigma_{0}-$ metal lattice resistance to free dislocation movement (lattice friction stress or PeierlsNabarro stress); $\Delta \sigma_{\text {s.s }}$ - solid solution strengthening by alloying elements and impurities (solid-solution strengthening); $\Delta \sigma_{\mathrm{gr}}, \Delta \sigma_{\mathrm{s}}$ - strengthening due to the change of the size of grain and subgrain (HallPetch dependencies - grain-boundary and subgrain strengthening); $\Delta \sigma_{\mathrm{d}}$ - dislocation strengthening due to interdislocation interaction; $\Delta \sigma_{\mathrm{d} . \mathrm{h}}$ - strengthening due to phase formation particles, according to Orowan (dispersion hardening).

Features of formation of local internal stresses $\tau_{\text {l.in }}$ - internal stress concentrators (their level, extent, interrelation with structural features of welded joint metal) were determined by dependence [6]:

$$
\tau_{1 . \text { in }}=G b h \rho /[\pi(1-v)] \text {, }
$$

where $G$ is the shear modulus; $b$ is the Burger's vector; $h=2 \cdot 10^{-5} \mathrm{~cm}$ is the foil thickness; $v$ is the Poisson's ratio; $\rho$ is the dislocation density.

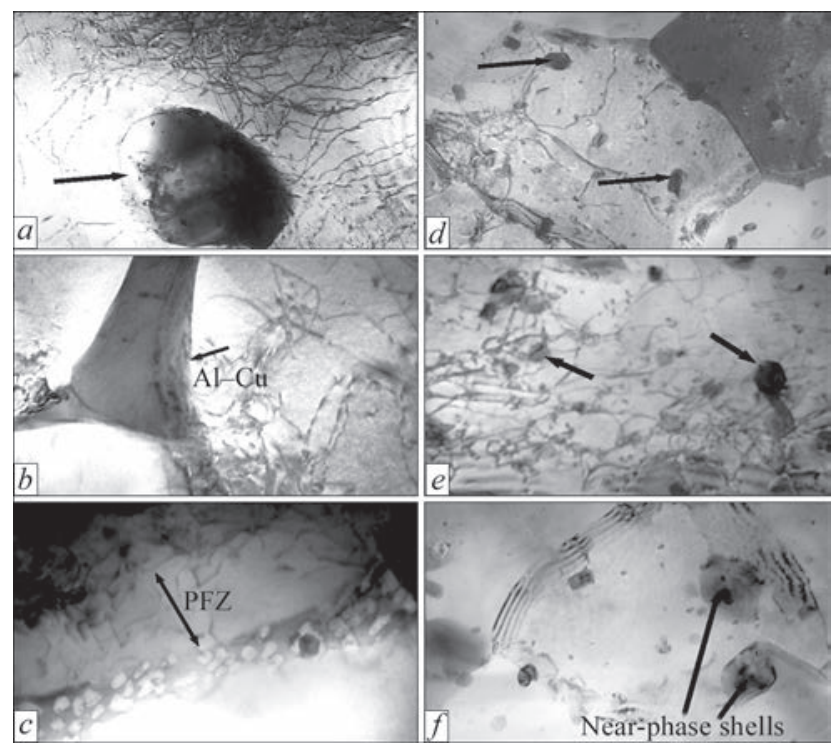

Figure 2. Phase distribution in grain volumes of metal of 1460 alloy weld produced by TIG welding ( $a-$ PP on grain inner volumes $(\times 2000)$; $b$ - extended grain-boundary eutectics $(\times 30000)$; $c$ - near-boundary PFZ $(\times 3000))$ and by FSW $(d, e-$ PP in grain volumes $(\times 30000) ; f$ - PP in grain-boundary zones of weld metal $(\times 30000))$
Investigation results. The following was established as a result of investigation of aluminium alloy TIG-welded joints produced without scandium alloying and those alloyed with scandium (Figure 1, $a, b$ ). Weld metal of joints of Al-Li alloy 1460 at application of Sv1201 filler (without scandium alloying) is primarily characterized by coarse-grained structure which is quite clearly revealed at investigation by optical microscopy method (Figure 1,a). More over, the TEM method reveals formation of coarse globular intragranular phase precipitates with $d_{\mathrm{Pp}}$ of up to $\sim 3.5 \mu \mathrm{m}$, extended massive intergranular eutectics of thickness $h_{\text {eut }}$ of up to $\sim 5 \mu \mathrm{m}$, as well as presence of precipitation-free zones (PFZ) along the grain boundaries. As is known, lowering of mechanical characteristics of welded joints is associated with the latter. Non-uniformity of dislocations distribution in weld metal of this type of joints is noted, particularly along extended near-boundary PFZ, where dislocation density decreases practically by an order (to $\rho$ $\left.=3 \cdot 10^{8} \mathrm{~cm}^{-2}\right)$, compared to intragranular dislocation density, where $\rho \sim(2-6) \cdot 10^{9} \mathrm{~cm}^{2}$ (Figure 2, $a-c$ ).

Now, under the conditions of weld metal alloying by scandium (up to $0.5 \%$ ), which is known to be the structure modifier after welding, certain changes are observed in the structure of welding zone metal, compared to respective structures in welded joints unalloyed by scandium. Such changes include, mainly, refinement of grain structure (see Figure 1,b), grain-boundary eutectics, dispersion of phase precipitates in grain volumes in combination with certain increase of dislocation density to $\rho \sim(4-9) \cdot 10^{9} \mathrm{~cm}^{-2}$.

Investigations of the features of structural changes at FSW revealed the following. Unlike significant grain coarsening by collective recrystallization mechanism, characteristic for fusion welding, considerable structure refinement (see Figure 1,c) is observed in FSW weld metal, which is associated with actively running processes of dynamic recrystallization, i.e. recrystallization by nucleation mechanism.

More over, structure of weld metal in FS-welded joints features an increase of overall dislocation den- 
sity up to $\rho \sim(3-6) \cdot 10^{10} \mathrm{~cm}^{-2}$, that is by an order of magnitude higher than volume dislocation density of weld metal in fusion welding (Figure $2, d, e$ ). Here, increase of intragranular dislocation density is accompanied by active redistribution of dislocations, that is indicated by formation of substructural elements, namely blocks, fragments, etc.

Apparently, structure refinement and activation of dislocation redistribution under the conditions of friction welding are due to intensive deformation of weld metal heated up to the plastic state and prevalence of dynamic recrystallization over collective one, respectively.

The next feature of structural state of weld metal produced under FSW conditions (compared to weld metal, produced by fusion welding) is an essential refining of PP (by 2.5 to 5 times) and an essential increase of their quantity at uniform distribution, being observed in all the weld metal zones - both in intragranular, and grain boundary volumes (see Figure 2, $d, e$ ).

Fragmentation of such problematic for aluminium alloys formations as grain-boundary eutectics also takes place. All these structural changes in the welding zone are provided by prevalence of thermodeformational processes in formation of structural-phase state of weld metal at FSW.

Complete range of investigations on different structural levels, which provides information about all structural factors formed in the welding zone and their parameters (size of grains, subgrains, chemical composition, dimensions, distribution and volume

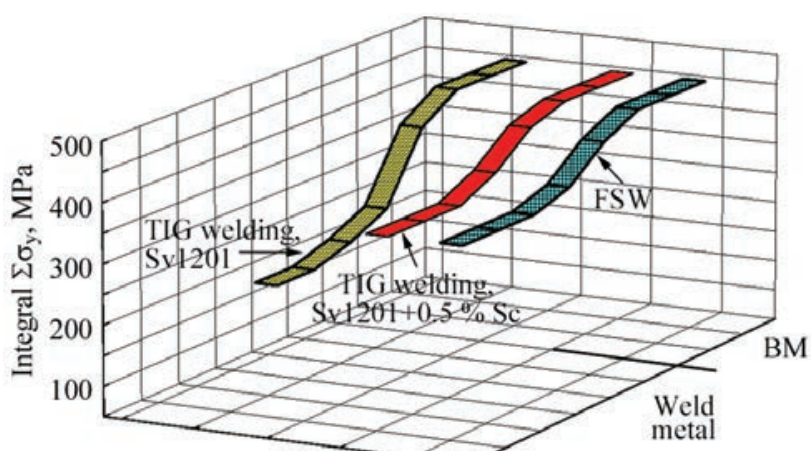

Figure 3. Change of integral $\Sigma \sigma_{y}$ at base-to-weld metal transition in aluminium alloy 1460 TIG-welded joints with Sv1201 and Sv1201 + 0.5Sc fillers and in FS-welded joint

fraction of strengthening phases, as well as dislocation structure), enables performing analytical evaluation of specific contribution of various structures in the studied zones, into the change of the most important service properties of welded joints, depending on the used welding modes.

Structure contribution into strength characteristics of $\mathrm{Al}-\mathrm{Li}$ welded joints. As a result of performed assessment of strength properties of studied joints with Sc and without it after TIG welding, the highest values are found in Sc-alloyed joints (Figure 3). Here, grain $\left(\Delta \sigma_{\mathrm{gr}} \sim 29 \%\right)$ and solid solution $\left(\Delta \sigma_{\text {s.s }} \sim 25 \%\right)$ strengthening make the greatest contribution into total (integral) value of yield point of metal of Sc-containing weld (Figure 4). And in the case without Sc alloying, the greatest contribution to total value of yield point is made, mainly, by solid solution strengthening $\left(\Delta \sigma_{\mathrm{s} . \mathrm{s}} \sim 28 \%\right)$ (see Figure 4$)$.

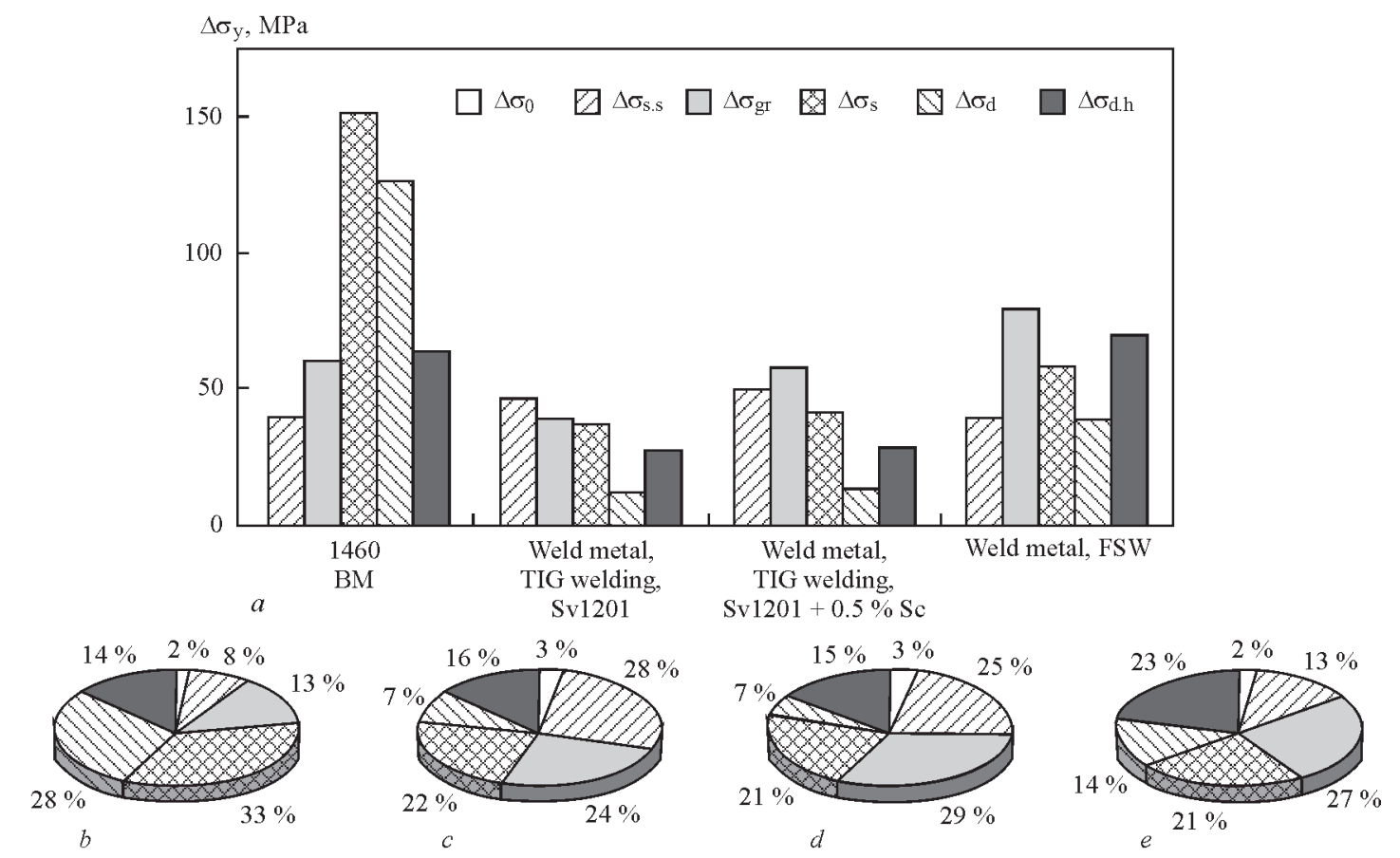

Figure 4. Histogram of differentiated contribution of structural constituents into the calculated value of $\Delta \sigma_{\mathrm{y}}(a)$, and pie charts $(b-e)$ showing percentage of structure contribution into total (integral) change of $\Sigma \sigma_{\mathrm{y}}$ in different studied zones: in base metal (b), in weld metal after TIG welding with Sv1201 (c) and Sv1201 + 0.5Sc (d) and after FSW (e) 


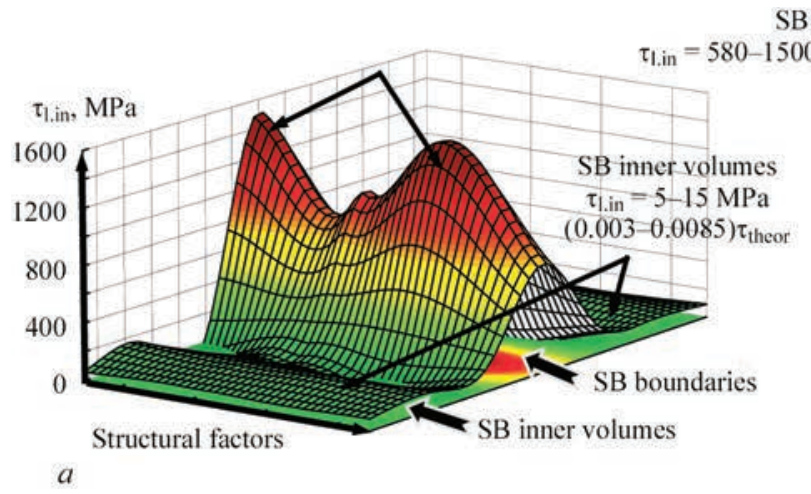

SB boundaries

$500 \mathrm{MPa},(0.34-0.85) \tau_{\text {theor }}$

Fragment

boundaries/volumes $\tau_{1 . \text { in }}=221-447 \mathrm{MPa}$

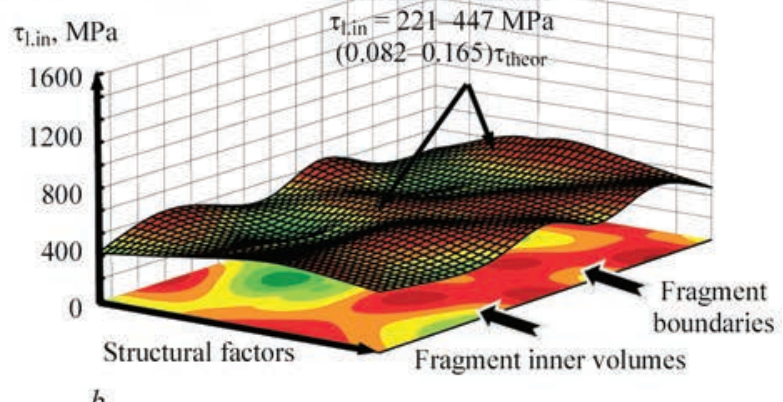

$b$

Figure 5. Distribution of $\tau_{\text {l.in }}$ in 1460 alloy weld metal: $a$ - TIG welding (weld metal without scandium); $b$ - FSW

Under FSW conditions, assessment of total (integral) value, $\Sigma \sigma_{\mathrm{y}}$ showed overall increase of strength values by $40 \%$, compared to those for conditions of TIG welding in the case without scandium (see Figure 3), that is ensured, mainly, by refinement of grain (up to $27 \%$ ) and subgrain (up to $21 \%$ ) structures and PP dispersion (up to $23 \%$ ) (see Figure 4).

Assessment of welded joint crack resistance. Comprehensive structural studies in combination with analytical evaluation also allowed clarifying the nature of structural factors influence on cracking processes in the welding zone of studied joints, which are due to the features of development of deformation localization zones, and local internal stresses $\left(\Delta \tau_{\text {l.in }}\right)$. This kind of investigations allows, first of all, determination of structures, influencing formation of $\tau_{\text {l.in }}$ to varying degrees.

Specific results of investigations and, primarily, nature of dislocation structure distribution in the studied samples, allowed assessment of $\tau_{\text {l.in }}$, determination of their level and extent. More over, respective investigations allow establishing structural factors, provoking growth of $\tau_{\text {l.in }}$ concentrators (i.e. processes of crack initiation and propagation), and determining which structural factors block such processes, negative in terms of metal properties, as cracking.

Analytical evaluations showed that under TIG welding conditions extended raisers of $\tau_{\text {l.in }}$ of up to $1500 \mathrm{MPa}$ $\left((0.34-0.85) \tau_{\text {theor }}\right)$ form in the metal without Sc, which exactly are the zones of crack initiation and propagation; and boundaries of powerful shear bands (SB) also belong to such zones (Figure 5, a). Contrarily, in SB inner volumes, $\tau_{\text {l.in }}$ values drop markedly (practically by 2 orders of magnitude) to $\sim 5-15 \mathrm{MPa}$ $\left.\left((0.0016-0.0055) \tau_{\text {theor }}\right)\right)$ that eventually creates a marked extended gradient of local internal stresses $\left(\Delta \tau_{1 . \mathrm{in}}\right)$, and, therefore, zone of crack initiation and propagation along SB boundaries (Figure 5,a).

Under FSW conditions, an essential lowering (by 3.5 times) of the $\tau_{\text {l.in }}$ (to $221-447 \mathrm{MPa}$ ) is observed in weld metal microstructure at uniform (without gra- dients) distribution of this type of local stresses over the entire volume of weld metal (Figure 5,b), that is exactly what ensures an increase of welded joint crack resistance.

Thus, to improve strength characteristics and crack resistance of welded joints of complex aluminium alloys, it is necessary to try to achieve formation of optimum structure that is provided by FSW, as shown by investigations of interrelation of structure and properties.

\section{Conclusions}

1. Comprehensive methods of investigation of welded joints of complex aluminium alloy 1460 enabled establishing the changes in key structural-phase parameters, influencing mechanical characteristics of welded joints at variation of the conditions of technological welding modes - from TIG (fusion) welding to FSW (solid-phase).

2. Under TIG welding conditions, weld metal is characterized by coarsening of grain structure, lowering of total volume density of dislocations, formation of globular intragranular and extended grain-boundary phase precipitates of eutectic type.

3. It is found that under the conditions of fusion welding, weld metal alloying by scandium leads to an essential change of structural-phase state of welded joints, namely, dispersion of grain and subgrain structure phase; increase of dislocation density at their uniform distribution; activation of phase formation processes in grain inner volumes, as well as fragmentation and reduction of volume fraction of grain-boundary eutectics.

4. Under FSW conditions, a marked refinement of grain and subgrain structure is observed, that is due to activation of fragmentation and nucleation processes, overall increase of dislocation density, as well as an essential dispersion of phase precipitates at their uniform distribution in intragrain and grain-boundary volumes.

5. For weld metal of aluminium alloy FS-welded joints, investigations with subsequent analytical as- 
sessment revealed that the considerable contribution (up to $40 \%$ ) to total strengthening of welded joints is provided by refinement of grain (up to $27 \%$ ) and subgrain (up to $21 \%$ ) structure, and dispersion of phase precipitates (up to $23 \%$ ), that significantly lowers the gradient of strength properties between base metal and weld metal and promotes a more uniform distribution of growing local internal stresses, and improvement of welded joint crack resistance, respectively.

6. Investigation of TIG welding modes showed that overall lowering of yield point values of weld metal is associated with coarsening of grain structure and reduction of overall dislocation density, that promotes an increase of gradient of strength characteristics between base metal and weld metal and lowering of welded joint crack resistance.

1. Fridlyander, I.N. (2000) Aluminium alloys in flying vehicles for periods of 1970-1999 and 2000-2015. In: Proc. of $5^{\text {th }}$ Session of Sci. Council on New Materials on Problems of Modern Materials Science, 15-19. Kiev: Naukova Dumka.

2. Goldshtejn, M.I., Litvinov, V.S., Bronfin, B.M. (1986) Metallophysics of high-strength alloys. Moscow: Metallurgiya.
3. Markashova, L.I., Alekseenko, T.A., Kushnaryova, O.S. et al. (2011) Role of structure in optimization of strength, ductility, crack resistance properties of welded joints. In: Building, Materials Science, Machine-Building: Transact., Issue 58, 446-452. Dnepropetrovsk: GVUZ PGASA.

4. Markashova, L., Kushnareva, O. (2014) Effect of structure on the mechanical properties of the metal of welded joints of aluminum alloys of the $\mathrm{Al}-\mathrm{Cu}-\mathrm{Li}$ system. Materials Sci., Vol. 49, Issue 5, 681-687.

5. Ashby, M.F. (1972) On the orowan stress. In: Physics of strength and plasticity, 88-107. Moscow: Metallurgiya.

6. Markashova, L.I., Ishchenko, A.Ya., Kushnaryova, O.S. et al. (2012) Effect of structural-phase transformations in aluminium-lithium alloy 1460 joints on physical-mechanical properties. The Paton Welding J., 5, 17-25.

7. Markashova, L.I., Poklyatsky, A.G., Kushnaryova, O.S. (2015) Role of structural-phase state in change of service properties of complexly-doped alloy welded joints. In: Building, Materials Science, Machine-Building: Transact., Issue 80, 191-195. Dnepropetrovsk: GVUZ PGASA.

8. Conrad, H. (1973) Model of strain hardening for explication of grain size effect on metal flow stress. In: Superfine grain in metals, 206-219. Moscow: Metallurgiya.

9. Petch, N.J. (1953) The cleavage strength of polycrystalline. $J$. Iron and Steel Inst., 173(1), 25-28.

10. Orowan, E. (1954) Dislocation in metals. New York: AIME.

Received 05.04.2016 